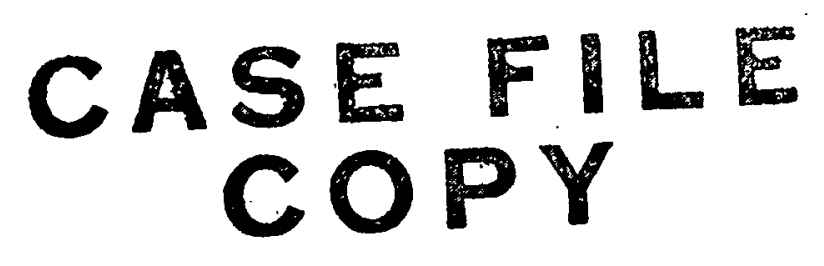

MEASUREMENT OF BEAM DIVERGENCE OF 30-CENTIMETER DISHED GRIDS

by Ronald L. Danilowicz, Vincent $\mathrm{K}$. Rawlin, Bruce A。Banks, and Edwin G。Wintucky

Lewis Research Center

Cleveland, Ohio 44135

TECHNICAL PAPER proposed for presentation at

- Tenth Electric Propulsion Conference sponsored by the American Institute of Aeronautics and Astronautics

- Lake Tahoe, Nevada, October 31-November 2, 1973 


\section{MEASUREMENT OF BEAM DIVERGENCE OF 30-CENTIMETER DISHED GRIDS}

Ronald L. Danilowicz, Vincent K. Rawlin, Bruce A. Banks, and Edwin G. Wintucky

National Aeronautics and Space Administration

Lewis Research Center

Cleveland, Ohio

\section{Abstract}

The beam divergence of a 30-centimeter diameter thruster with dished grids was calculated from current densities measured with a probe rake containing seventeen planar molybdenum probes. The measured data were analyzed as a function of a number of parameters. The most sensitive parameters were the amount of compensation of the accelerator grid and the ratio of net to total accelerating voltage. The thrust losses were reduced by over 5 percent with the use of compensated grids alone, and by variation of other parameters the overall thrust losses due to beam divergence were reduced to less than 2 percent.

\section{Introduction}

The electron bombardment ion thruster is being considered for a variety of missions for which the optimum specific 1mpulse is between 2000 and 3000 seconds (refs. 1 and 2). Dished grids (ref. 3) appear attractive for operation in this specific $1 \mathrm{~m}-$ pulse range. Thrust losses due to the use of this type of grid system need, however, to be considered. Ion beam profiles with dished grids are affected by many parameters. This paper presents an experimental investigation of the thrust losses due to ion beam divergence as a function of grid type and geometry over a wide range of thruster operating conditions. Parameters studied included the ratio of net-to-total accelerating voltage, total accelerating voltage, grid hole size, grid percent open area, dish depth, grid spacing, and total ion beam current. In addition, several compensated grid sets for which the center-to-center hole spacing differed for the accelerator and screen grid were tested to determine the effect of hole compensation on beam divergence.

\section{Apparatus and Procedure}

\section{Thruster and Facility}

The ion beam measurements were all made using a 30-centimeter diameter thruster built by Hughes Research Laboratories (HRL) under Contract NAS3-14140 (ref. 4). The thruster was modified in the course of a separate discharge chamber optimization program. Details of the thruster configurations are presented in a companion conference paper (ref. 5). Twenty-seven different accelerator grid sets were studied during the program. All grid geometry data are presented in table $I$. These were fabricated by a hydroforming technique similar to that described in reference 3 . For some of the grid sets the accelerator grid was stretched prior to hydroforming to compensate for the misalinement normally assoctated with dished grids. The thruster was operated in the 3.0-meter diameter port of the 7.6-meter diameter by 21.4-meter long vacuum tank at the Lewis Research Center (ref. 6). The bell jar pressure was about $3 \times 10^{-6}$ torr while the main tank pressure was about $2 \times 10^{-7}$ torr during thruster operation.
All of the data were taken at a constant discharge voltage of 37 volts.

\section{Beam Probe}

The measurements were taken with a probe rake consisting of seventeen 1.27-centimeter diameter, planar molybdenum probes. These were equally spaced 15.24 centimeters apart. Each probe was completely shielded on the sides so that current was collected only on the 1.27-centimeter diameter circular face of the probe. This was necessary to define accurately the collecting area. This beam probe rake was swept in an arc in a plane perpendicular to the thruster centerline. This plane was located at both 1.37 or 1.83 meters downstream of the thruster grid system.

The data from the probe rake is automatically recorded using the Central Automatic Digital Data Encoder (CADDE II) system (ref. 7). Data is taken sequentially at a rate of approximately 27 points per second. Potentiometer values are recorded that indicate the position of the probe rake at the beginning and end of each scan of the 17 probes. From these values the position of each probe was determined for the time of its individual reading. Typically, about 45 seconds were required to sweep the rake across the Ion beam, and data were taken from each probe approximately 60 times. A total of about 1000 values of current were recorded on magnetic tape.

\section{Computer Code}

These data were reduced and analyzed using a digital computer code run on an IBM $7040 / 7094$ direct couple system. The raw data were initially converted into current densities as a function of position. Curve fitting methods (ref. 8) then applied to these values resulted in piecewise continuous functions, continuous in both value and slope, which fit successive intervals of data. These curve fits are used in generating contour plots and also for the integration routines used in analyzing the data.

The integrals necessary to calculate total ton current $\mathrm{J}_{\mathrm{B}}$ and the ratio of actual axial thrust to ideal axial thrust $T$ (hereinafter referred to as the thrust factor), were evaluated using a 65 point guass-quadrature numerical integration routine. These quantities were calculated from the following expressions:

$$
J_{B}=\int_{0}^{2 \pi} \int_{0}^{\infty} j(r, \theta) r d r d \theta
$$




$$
T=\frac{\int_{0}^{2 \pi} \int_{0}^{\infty} j(r, \theta) \cos \psi r d r d \theta}{\int_{0}^{2 \pi} \int_{0}^{\infty} j(r, \theta) r d r d \theta}
$$

where $j(r, \theta)$ is the measured current density at $r$ and $\theta$, cylindrical coordinates in the plane of the probe rake. The coordinate $r$ is measured with respect to the centerline of the thruster and $\psi$ is the angle between the centerline and the line joining the point $(r, \theta)$ to the center of the accelerator grid.

\section{Grid Fabrication}

All the dished grids discussed in this paper were fabricated by a hydroforming technique, simflar to that given in reference 3 . Some of the grid sets had larger center-to-center spacing for the accelerator grid to determine the effect on the thrust factor. Several techniques $c$ an be used to make the aperature array spacing of the accelerator grid slightly larger (and thus compensating) than that of the screen grid. One technique is to have two different array spaced photoetching master patterns made. Another technique is to use the same array spacing for both the screen and accelerator grid photoetching master pattern but stretch the accelerator grid prior to hydroforming with the screen grid. This latter technique was used for most of the compensated grids discussed in this paper.

The fabrication technique used to stretch the grids to produce a permanent strain consisted of forcing the accelerator grid into a pie pan shape. A stretching system shown in figure 1 was inserted Into a hydroforming system shown in figure 2. The grids were either perforated or had a photoresist hole pattern on them prior to stretching. Applying pressure to the water in the upper chamber of the hydroforming system causes the grid to be tightly clamped around its edge. A wedge shaped groove in the clamping ring further prevented irregular slippage of the grid. The application of water pressure to the lower portion of the system caused a disk of metal to be forced into the initially flat accelerator grid. The amount of stretching, $E$, was varied by control of the pressure used to raise the metal disk. To prevent scratches on the grids which have photoresist patterns on them the disk had a raised smooth ridge at its edge. After the stretching was accomplished the central flat portion of the grid was cut out, alined with an unstretched screen grid, and as a pair then simultaneously hydroformed using a clamping ring shown in figure 2. The clamping ring allows the grids to hydroform to a natural near-spherical contour. The clamping $r$ ing also has a wedge shaped slippage preventing groove machined into it. The groove was found to be important because without it slippage was found to occur causing non-spherical grid contours and local surface flat spots.

\section{Results and Discussion}

This section will present the beam divergence and thrust losses associated with a large number of dished grid geometries and thruster operating conditions. Attempts will be made to separate the effect of varlous parameters on the thrust losses. Because both the screen and accelerator grid are simultaneously hydroformed, the resulting screen and accelerator grids have a geometry shown in $\mathrm{fig}$ ure 3a. For thruster operation the grids are separated by axially displacing one grid downstream of the other, this results in a grid geometry shown in figure $3 b$. As a result of this geometry there are three thrust losses for each ion beamlet.

The first thrust loss is caused by the misalinement of the screen and accelerator aperatures. This misalinement causes an ion beamlet deflection of an angle $\lambda$. All symbols are defined in appendix $A$ and in figure $3 b$. The second thrust loss is due to the dished grid curvature (associated with the angle $\gamma$ ). Thus, the thrust vector for each beamlet is at an angle of $\lambda+\gamma$ from the thruster axis. Both of these losses are a direct result of the dished shape and do not exist for flat grids.

The third thrust loss is due to the divergence of the ion trajectories comprising each beamlet. This loss probably depends upon the aperature geometry, ion sheath shape, and the applied potentials. Theoretical beamlet divergence studies have been investigated in references 9 and 10 .

The thrust loss associated with the angle $\lambda$ can be eliminated if the dished grid geometry can be made with its aperatures co-axial as shown in figure $3 \mathrm{c}$. Further reduction of the $\gamma$ thrust loss can be achfeved by properly misalining the aperatures so that negative $\lambda$ values are obtained. Thus, for $\lambda=-\gamma$ as shown in figure 3d the resultant ion beamlet vectors are axially directed and only beamlet divergence losses are incurred.

The thrust losses will be discussed from the three general sources in the following order: (1) hole misalinement, (2) grid curvature, and (3) losses due to ion curvatures in individual beamlets. To assess the effects of hole misalinement the thrust losses as a function of grid compensation, percent open area, and grid spacing on thrust losses are presented. The effects of dish depth on thrust losses are discussed next. Lastly, the effects of parameters which change the trajectories in each individual beamlet are discussed. These include hole size, total ion beam current, total accelerating voltage, and the ratto of netto-total accelerating voltage. For the sake of completeness all of the data taken are presented in table II. The data is separated into two sections corresponding to the two probe positions. As mentioned earlier, a number of different thrusters were run during the course of this study. Since the thrust factor was not sensitive to thruster variation this information is not included in the table.

\section{Hole Misalinement}

By far the largest improvement in thrust factor was accomplished by the use of dished grid sets where the accelerator grid was compensated to minimize thrust losses. Figure 4 shows the thrust factor as a function of strain of the accelerator grid (grid sets $B 1, C l, D 1$, and $E 1$ ). This effect can also be seen dramatically in figure 5 which presents computer generated contour plots from the 
probe rake data for grids for which the strain of the accelerator grid, $\varepsilon$, was $0.0000,0.0022$, and 0.0066 , respectively. The contour plots show very effectively how the compensated grids narrow the spread in the thruster beam. It is interesting to note from figure 4 that the best experimental strain for the accelerator grid appears to be larger than the value predicted by the expression for $\varepsilon_{\lambda=-\gamma}$ given in appendix $B$. Using the parameters for grid sets $B 1, C 1, D 1$, and $E 1$ from table I gives $\varepsilon_{\lambda=-\gamma}=0.0045$. Note that one 1fmit on the best experimental strain would be when direct ion impingement begins to occur. This occurs only for grid set $\mathrm{K} 1$ in this study.

The percent open area of the grids was also varled. Data from grid set BI ( 51 percent open area) can be compared with data from grid set F2 (67 percent open area). Both are uncompensated grid sets. Data run numbers 65,68 , and 69 when compared with runs 81,85 , and 86 , respectively, show that the increase in open area from 51 to 67 percent caused approximately a 0.6 percent decrease in thrust factor. It is possible that for the higher open area grids that the sheaths from neighboring grid holes overlap in such a way as to amplify the effects of misalinement. This point is discussed in more detafl in a companion paper (ref. 5).

The cold grid gap was varted on a number of grid sets. The effect on the thrust factor was quite small. Sma11 variations in the cold gap actually led to data that sometimes increased and sometimes decreased the thrust factor. For grid set $P$ where the gap was decreased by more than a factor of two the thrust factor increased by only 0.4 percent.

\section{Grid Curvature}

Data were taken with two hexagonal hole grid sets (grid sets $O$ and $P$ ) with different dish depths. Grid set 0 with the shallower dish also had an accelerator grid that was slightly compensated $(\varepsilon=0.00097)$ making quantitative comparisons difficult. Grid set 0 did lead to less thrust loss. However, how much of the improvement came from the shallower dish shape and how much from the compensation of the accelerator grid can not be determined.

\section{Individua1 Beamlet Losses}

The remaining parameters primarily affect the distribution of ions within the individual beamlets from each set of holes. Run numbers 81,85 , and 86 (grid set B1) when compared with run numbers 100 to 102 (grid set Al), respectively, show the effect of hole size on the thrust factor. An increase in hole diameter from 0.102 to 0.178 centimeter corresponded to approximately a 0.5 percent gain in the thrust factor. Comparisons of runs 20 (grid set G1) against 42 (grid set FI) and 113 (grid set M2) against 129 (grid set H1) further show thrust factor gains of 0.8 and 0.3 percent, respectively, with an increase in hole diameter. This is probably due to the spreading out of the ion trajectorfes in the individual beamlets for the smaller holes.

Figure 6 shows the effect of total ion beam current $J_{B}$ on the thrust factor with both compensated and uncompensated grids. These data were taken for almost every grid set. Typlcally, there was no change in thrust factor with total fon beam current for uncompensated grids. On the other hand with the compensated grid sets there was an increase in thrust factor with total ion beam current.

It has not been determined why these differences occur. Close beam traces within a few centimeters of the thruster showed no change in normalized beam profile with total ion current for any of the grids studied. Also, the deliberate misalinement of the compensated grids is always much larger than the orlginal slight misalinement of the uncompensated grids. It is possible that a fixed amount of compensation leads to varying amounts of deflection with increased beam current. This could account for the differences in thrust factor with beam current for the uncompensated and compensated grid sets.

Figure 7 shows the effect of $R$ ratio (screen voltage $v_{I}$ divided by total voltage $v_{I}+\left|v_{A}\right|$ ) on the thrust factor. The data were taken three ways: with $V_{I}$ constant (grid sets $\mathrm{L} 1$ and $\mathrm{HI}$ ), with $V_{A}$ constant (grid set $H 1$ ), and with $V_{I}+$ $\left|V_{A}\right|$ constant (grid set L1). It can be seen from the data in table II that higher $R$ ratios led to higher thrust factors regardless of which way the data were taken. This Indicates that total voltage is not important, only the $R$ ratio is. Therefore, thrust losses can be reduced by operating a thruster at as high an $R$ ratio as possible without backstreaming.

\section{Error Analysis}

In the discussions of the data above 1 it is desirable to have some indication of the repeatability of the data. Twenty-nine runs in the table are repeated. Sometimes points were repeated when it was not certain that the data had been received proper1y by the CADDE system. In addition some earlier runs (grid set Fl, runs 34-41) were made with some variations which it was felt would not affect the thrust factor. Varied in these runs were probe speed, position on the ev/ionutilization curve, neutralizer flow rate, and the differences with other nearby facilities being on or off. For these eight runs the thrust factor was either 0.905 or 0.906 indicating that the data were quite repeatable. The only repeated data which were different by more than 0.2 percent were points 169 and 170 which differed by 0.3 percent and points 148 and 150 which differed by 0.4 percent.

As mentioned in the section on the computer code it is assumed in calculating the thrust factor that all of the current comes from a point source at the center of the grids. This approximation leads to overestimates in the calculated thrust losses. This is because current from the outer portions of the grids to a particular probe position will arrive more nearly perpendicular to the probe than assumed for the point source approximation. The farther the probe rake is from the grids the better the point source approximation becomes. The data up to run number 182 were taken with the probe rake 1.37 meters downstream of the grids. The data for run numbers 183 and higher were taken with the probe rake 1.83 meters downstream of the grids. Because of the point source approximation Improving with the increase in this distance, the later data 
leads to thrust factors approximately 1 percent higher than the earlier data. At this distance the point source approximation is still undercalculating the thrust factor by some unknown amount.

The molybdenum probes were biased negatively to repel thermal electrons. As part of this study the effects of secondary electron emission on the data using a Faraday cup indicated that this had less than a 0.5 percent effect on the current densities measured. Another indication that the measured current densities were accurate was that calculated values of total ion current were almost always within 2 percent of the meter value. The effect on the thrust factor would be a very small fraction of a percent since the current densitfes appear in both the numerator and denominator of the expression for $T$.

Computer errors due to curve fitting the data and the integration techniques used are estimated to be less than 0.2 percent. The effects of double ionization on the thrust factor have been ignored in this study and are unknown at this time.

\section{Conclusions}

A procedure has been developed for accurately measuring beam divergence from 30-centimeter diameter dished grids. Techniques have also been developed for stretching the accelerator grid of a grid set to compensate for thrust losses inherent in a dished grid system. Through the variation of a number of patameters it was possible to reduce the thrust losses from beam divergence to less than 2 percent. Futther reductions in thrust loss will probably be small since some beam divergence will always be present due to the ion trajectories in individual beanlets not being perfectly parallel.

\section{Appendix A}

Symbol List

grid gap, m

h dish depth, m

$j$ current density, $a m p / m^{2}$

$J_{B} \quad$ total ton beam current, amp

$k$ constant of proportionality, dimensionless

$\ell$ arc length from grid center to outermost active grid hole, m

$R$ ratio of net to total accelerating voltage, dimensionless

$R$ radius of curvature of dished grid, $m$

radius as defined in equations (1) and (2),

$r_{D}$ radius of the dished portion of the grid, m

$r_{H}$ radius of the outermost active region of the dished grid, m

thrust factor, dimensionless

${ }_{A}$ accelerator grid thickness, $m$

\begin{tabular}{|c|c|}
\hline $\mathrm{V}_{\mathbf{I}}$ & screen voltage, volts \\
\hline $\mathrm{V}_{\mathrm{A}}$ & accelerating voltage, volts \\
\hline$\gamma$ & $\begin{array}{l}\text { angle between the thruster axis and a line } \\
\text { perpendicular to the grid surface at the } \\
\text { outermost active hole, radians }\end{array}$ \\
\hline$\Delta \ell$ & change in $l$ due to stretching grid, II \\
\hline$\delta$ & $\begin{array}{l}\text { misalinement of the outermost holes re- } \\
\text { quired to produce para-axial beamlets, w }\end{array}$ \\
\hline$\varepsilon$ & strain, dimensionless \\
\hline$\varepsilon_{\lambda=0}$ & $\begin{array}{l}\text { strain required to produce co-axial screen } \\
\text { and accelerator grid holes, dimensionless }\end{array}$ \\
\hline$\varepsilon_{\lambda=-\gamma}$ & $\begin{array}{l}\text { strain required to produce para-axial ion } \\
\text { beamlets, dimensionless }\end{array}$ \\
\hline$\psi$ & $\begin{array}{l}\text { angle defined in equations (1) and ( } 2 \text {, } \\
\text { radians }\end{array}$ \\
\hline$\theta$ & $\begin{array}{l}\text { angle defined in equations (1) and (2), } \\
\text { radians }\end{array}$ \\
\hline
\end{tabular}

Appendix B

\section{Strain Compensation Required For Reduction of Dished Grid Thrust Losses}

The required strain of the accelerator grid, $\varepsilon_{\lambda=0}$, to compensate for the $\lambda$ thrust loss for outermost holes is a function of grid gap $g$, screen grid thickness $t_{s}$, accelerator grid thickness $t_{A}$, dished grid radius of curvature $R$, and the angle $\gamma$ between the thruster axis and a line perpendicular to the grid surface at the outermost active hole. Relating these variables through the use of figure 3 one obtains

$$
\varepsilon_{\lambda=0}=\frac{\Delta \ell}{\ell}
$$

or

$$
\varepsilon_{\lambda}=\frac{g+\left(\frac{t_{s}+t_{A}}{2 \cos \gamma}\right) \sin \gamma}{R \gamma}
$$

but

$$
R^{2}=r_{D}^{2}+(R-h)^{2}
$$

so that

$$
R=\frac{x_{D}^{2}+h^{2}}{2 h}
$$

and

$$
\sin \gamma=\frac{2 r_{H} h}{r_{D}^{2}+h^{2}}
$$

Using these relations an expression for $\varepsilon_{\lambda=0}$ can be obtalned. 


$$
\varepsilon_{\lambda=0}=\frac{2 r_{H^{2}} h^{2}\left(\frac{2 g}{r_{D}^{2}+h^{2}}+\frac{t_{S}+t_{A}}{r_{D}^{2}-h^{2}}\right)}{\left(r_{D}^{2}+h^{2}\right) \arcsin \left(\frac{2 r_{H} h}{r_{D}^{2}+h^{2}}\right)}
$$

This represents a geometry in which the outermost holes are in the proper position to have coaxial hole centerlines. For example if $g=0.0635$ centimeter ( 0.025 in.), $t_{s}=0.0381$ centimeter ( 0.015 in.), $t_{A}=0.0762$ (0.030 in.), $h=2.286$ centimeter ( 0.9 in.), $2 \mathrm{r}_{\mathrm{H}}=28.448$ centimeters (11.2 in.) and $2 \mathrm{r}_{\mathrm{D}}=30.480$ centimeters $(12.0 \mathrm{in.})$ then $\varepsilon_{\lambda=0}=0.00234$.

Compensation to produce para-axial beamlets requires additional stretching and the total strain is given by

$$
\varepsilon_{\lambda=-\gamma}=\varepsilon_{\lambda=0}^{\prime}+\frac{\delta}{R \gamma}
$$

where $\delta$ is the misalinement of the outermost holes to produce para-axial beamlets. Lathem and Adam have shown in references 9 and 10 for a given grid geometry, spacing, and beam current deflection, that $\gamma$ is approximately proportional to the grid translation fraction $\delta / d_{A}$, where $d_{A}$ is the accelerator hole diameter. then

Thus, if $k$ is the constant of proportionality

$$
\text { or } \quad \begin{aligned}
\gamma & =k \frac{\delta}{d_{A}} \\
\delta & =\frac{\gamma d_{A}}{k}
\end{aligned}
$$

and

$$
\varepsilon_{\lambda=-\gamma}=\varepsilon_{\lambda=0}+\frac{\gamma d A}{R k \gamma}
$$

or

$$
\varepsilon_{\lambda=-\gamma}=\varepsilon_{\lambda=0}+\frac{d_{A}}{R k}
$$

and

$$
\varepsilon_{\lambda=-\gamma}=\frac{2 r_{H} h^{2}\left(\frac{2 g}{r_{D}^{2}+h^{2}}+\frac{t_{s}+t_{A}}{r_{D}^{2}-h^{2}}\right)}{\left(r_{D}^{2}+h^{2}\right) \arcsin \left(\frac{2 r_{H}^{h}}{r_{D}^{2}+h^{2}}\right)}+\frac{2 h d_{A}}{\left(r_{D}^{2}+h^{2}\right) k}
$$

Values of $k$ in reference 10 vary from 1.84 to 1.33 depending upon the grid system geometry, grid

\begin{tabular}{|c|c|c|c|c|c|c|c|c|c|c|c|}
\hline \multirow[t]{2}{*}{$\begin{array}{c}\text { Grid } \\
\text { set }\end{array}$} & \multicolumn{2}{|c|}{$\begin{array}{l}\text { Hole Diam, } \\
\text { mm }\end{array}$} & \multicolumn{2}{|c|}{$\begin{array}{c}\text { Grid Thickness, } \\
\text { man }\end{array}$} & \multicolumn{2}{|c|}{$\begin{array}{l}\text { Open Area } \\
\text { Fraction }\end{array}$} & \multirow{2}{*}{$\frac{\text { Strain }}{\%}$} & \multirow{2}{*}{$\begin{array}{l}\text { Dish Depth } \\
\text { to } \\
\text { Dish Diam } \\
\text { Ratio }\end{array}$} & \multirow[t]{2}{*}{ Hole Shape } & \multirow{2}{*}{$\begin{array}{l}\text { Cold Grid } \\
\text { To Grid } \\
\text { Spacing, } \\
\text { mm }\end{array}$} & \multirow[t]{2}{*}{$\begin{array}{l}\text { Run Nos. } \\
\text { Table II }\end{array}$} \\
\hline & Screen & Accel & Screen & Accel & Screen & Accel & & & & & \\
\hline $\mathrm{Al}$ & 1.02 & 1.02 & 0.38 & $0 . \overline{38}$ & 0.51 & 0.51 & 0 & 0.075 & Circular & 0.64 & $100-106$ \\
\hline $\begin{array}{l}\text { B1 } \\
\text { B2 } \\
\text { B3 }\end{array}$ & 1.91 & 1.91 & 0.38 & 0.38 & 0.51 & 0.51 & 0 & 0.075 & Circular & $\begin{array}{l}0.64 \\
0.66 \\
0.99\end{array}$ & $\begin{array}{l}81-86 \\
48-63 \\
45-47\end{array}$ \\
\hline $\mathrm{CI}$ & 1.91 & 1.91 & 0.38 & 0.38 & 0.51 & 0.51 & 0.22 & 0.075 & Circular & 0.64 & $71-80$ \\
\hline DI & 1.91 & 1.91 & 0.38 & 0.38 & 0.51 & 0.51 & 0.44 & 0.075 & Circular & 0.86 & $218-239$ \\
\hline $\begin{array}{l}\text { E1 } \\
\text { E2 } \\
\text { E3 }\end{array}$ & 1.91 & 1.91 & 0.38 & 0.38 & 0.51 & 0.51 & $i^{0.66}$ & 0.075 & Circular & $\begin{array}{l}0.76 \\
0.84 \\
1.09\end{array}$ & $\begin{array}{c}188-195 \\
144-166 \\
93-99\end{array}$ \\
\hline $\begin{array}{l}\mathrm{F} 1 \\
\mathrm{~F} 2\end{array}$ & $\begin{array}{l}\frac{1}{1.91} \\
1.91\end{array}$ & $\begin{array}{l}1.91 \\
1.91\end{array}$ & $\begin{array}{l}1 \\
0.38 \\
0.38\end{array}$ & $\begin{array}{l}0.38 \\
0.38\end{array}$ & $\begin{array}{l}1 \\
0.6^{7} \\
0.67\end{array}$ & $\begin{array}{l}0.67 \\
0.67\end{array}$ & $\begin{array}{l}\frac{1}{0} \\
0\end{array}$ & $\begin{array}{l}\frac{1}{0.075} \\
0.075\end{array}$ & $\begin{array}{l}\text { Circular } \\
\text { Circular }\end{array}$ & $\begin{array}{l}1.03 \\
0.74 \\
0.76\end{array}$ & $\begin{array}{l}28-43 \\
65-69, \\
143,167 \\
196-201\end{array}$ \\
\hline $\begin{array}{l}\mathrm{GI} \\
\mathrm{G} 2\end{array}$ & $\begin{array}{l}2.41 \\
2.41\end{array}$ & $\begin{array}{l}2.41 \\
2.41\end{array}$ & $\begin{array}{l}0.38 \\
0.38\end{array}$ & $\begin{array}{l}0.38 \\
0.38\end{array}$ & $\begin{array}{l}0.67 \\
0.67\end{array}$ & $\begin{array}{l}0.67 \\
0.67\end{array}$ & $\begin{array}{l}0 \\
0\end{array}$ & $\begin{array}{l}0.075 \\
0.075\end{array}$ & $\begin{array}{l}\text { Circular } \\
\text { Circular }\end{array}$ & $\begin{array}{l}0.64 \\
1.14\end{array}$ & $\begin{array}{c}20,107 \\
22\end{array}$ \\
\hline $\begin{array}{l}\mathrm{H} 1 \\
\mathrm{H} 2 \\
\mathrm{H} 3\end{array}$ & 1.91 & 1.52 & 0.38 & 0.76 & 0.67 & 0.43 & 0 & 0.075 & Circular & $\begin{array}{l}1.69 \\
0.69 \\
0.84 \\
1.30\end{array}$ & $\begin{array}{c}128-142 \\
202,214 \\
87-88\end{array}$ \\
\hline $\mathrm{J} 1$ & 1.91 & 1.52 & 0.38 & 0.76 & 0.67 & 0.43 & 0.35 & 0.075 & Circular & 0.81 & $207-213$ \\
\hline $\mathrm{KI}$ & 1.91 & 1.52 & 0.38 & 0.76 & 0.67 & $0 . \overline{3}$ & 1.3 & 0.075 & Circular & 0.51 & 215,217 \\
\hline$\overline{\mathrm{Ll}}$ & 2.16 & 1.73 & 0.38 & 0.76 & 0.67 & 0.43 & 0 & 0.075 & Circular & 1.02 & $115-127$ \\
\hline $\mathrm{MI}$ & 2.41 & 1.93 & 0.38 & 0.76 & 0.67 & 0.43 & 0 & 0.075 & Circular & 0.94 & 114 \\
\hline M2 & 2.41 & 1.93 & 0.38 & 0.76 & 0.67 & 0.43 & 0 & 0.075 & Circular & 1.24 & $108-113$ \\
\hline N1 & 2.41 & 1.93 & 0.38 & 0.76 & 0.67 & 0.43 & 0.25 & 0.038 & Circular & 0.89 & $240-244$ \\
\hline $\begin{array}{l}01 \\
02\end{array}$ & $\begin{array}{l}2.08 \\
2.08\end{array}$ & $\begin{array}{l}2.08 \\
2.08\end{array}$ & $\begin{array}{l}0.38 \\
0.38\end{array}$ & $\begin{array}{l}0.38 \\
0.38\end{array}$ & $\begin{array}{l}0.77 \\
0.77\end{array}$ & $\begin{array}{l}0.77 \\
0.77\end{array}$ & $\begin{array}{l}0 \\
0\end{array}$ & $\begin{array}{l}0.075 \\
0.075\end{array}$ & $\begin{array}{l}\text { Hexagonal } \\
\text { Hexagonal }\end{array}$ & 0.91 & $\begin{array}{c}90 \\
91,92\end{array}$ \\
\hline $\begin{array}{l}\text { P1 } \\
\text { P2 } \\
\text { P3 }\end{array}$ & $\frac{2.08}{2.08}$ & $\frac{2.08}{2.08}$ & 0.38 & $\frac{0.38}{0.38}$ & 0.77 & 0.77 & 0.097 & 0.038 & Hexagonal & $\begin{array}{l}1.14 \\
0.91 \\
1.17 \\
1.98\end{array}$ & $\begin{array}{l}\frac{11}{177}-187 \\
173-176 \\
168-172\end{array}$ \\
\hline
\end{tabular}
gap, and ion beam current. The first and second term of the $\varepsilon_{\lambda}=-\gamma$ equation are of near equal magnitude. It can also be shown that this value of strain is within $1 / 2$ percent of the ideal strain value for the entire grid face even though the ca1culation was made for the outermost active holes.

Table I Dished Grid Geometries 
Table II Thrust Factor Data

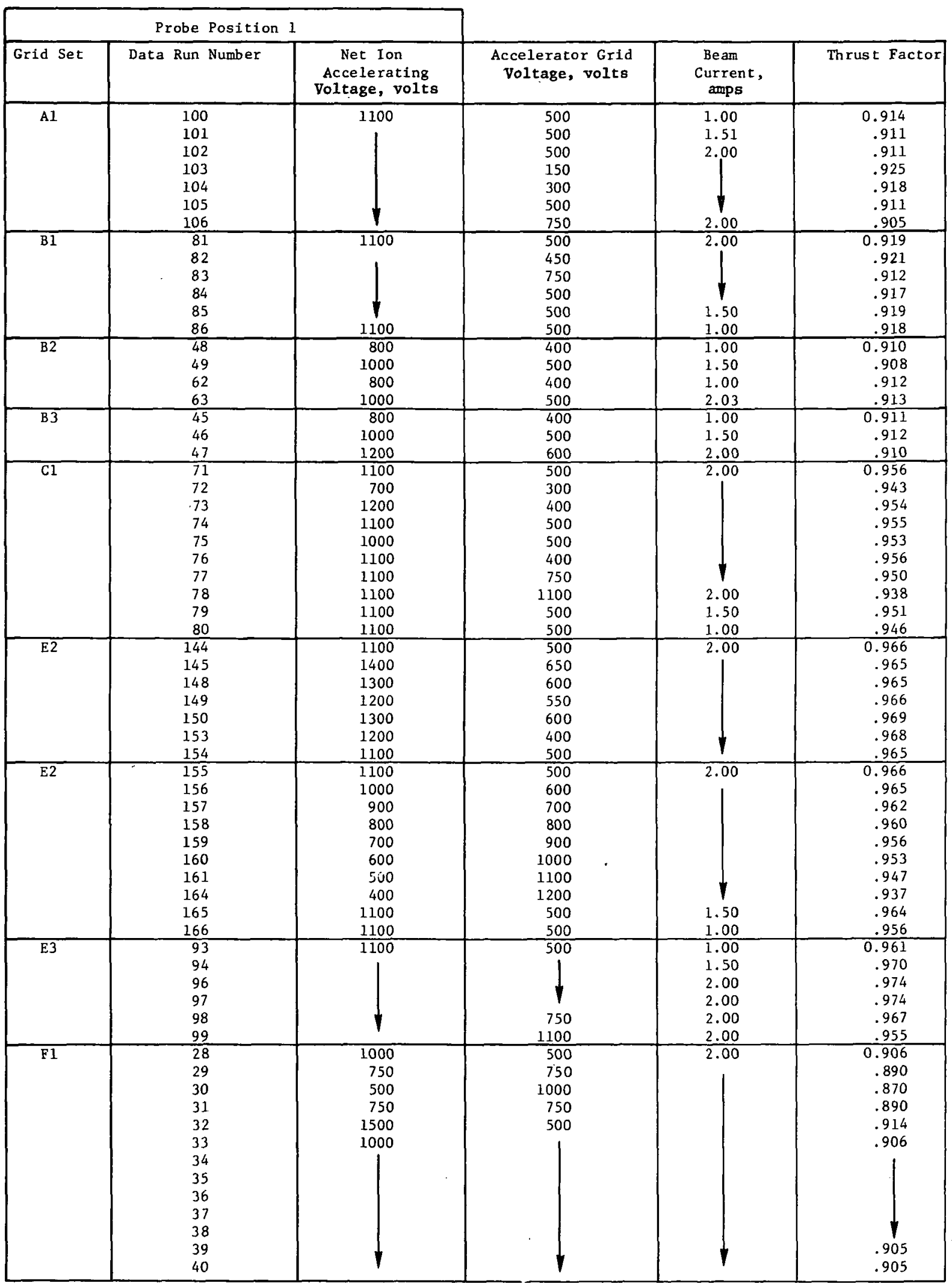


Table II Continued

\begin{tabular}{|c|c|c|c|c|c|}
\hline Grid Set & Data Run Number & $\begin{array}{c}\text { Net Ion } \\
\text { Accelerating } \\
\text { Voltage, volts }\end{array}$ & $\begin{array}{l}\text { Accelerator Grid } \\
\text { Voltage, volts }\end{array}$ & $\begin{array}{l}\text { Beam } \\
\text { Current, } \\
\text { amps }\end{array}$ & Thrust Factor \\
\hline F1 & $\begin{array}{l}41 \\
42 \\
43\end{array}$ & $\begin{array}{l}1000 \\
1200 \\
1200\end{array}$ & $\begin{array}{l}500 \\
600 \\
600\end{array}$ & $\begin{array}{l}2.00 \\
2.50 \\
2.50\end{array}$ & $\begin{array}{r}0.906 \\
.906 \\
.907\end{array}$ \\
\hline $\mathrm{F} 2$ & $\begin{array}{r}65 \\
66 \\
67 \\
68 \\
69 \\
143 \\
167 \\
\end{array}$ & $\begin{array}{l}1100 \\
1300 \\
1100 \\
1100\end{array}$ & 500 & $\begin{array}{l}2.00 \\
2.00 \\
2.00 \\
1.50 \\
1.00 \\
1.99 \\
2.01 \\
\end{array}$ & $\begin{array}{r}0.913 \\
.914 \\
.914 \\
.915 \\
.912 \\
.912 \\
.908 \\
\end{array}$ \\
\hline$G 1$ & 20 & 1200 & 600 & 2.50 & 0.914 \\
\hline $\mathrm{G} 2$ & 22 & 1460 & 870 & 3.00 & 0.910 \\
\hline H1 & $\begin{array}{l}128 \\
129 \\
131 \\
132 \\
133 \\
135 \\
136 \\
137 \\
138 \\
139 \\
140 \\
141 \\
142\end{array}$ & $\begin{array}{r}1100 \\
1100 \\
700 \\
900 \\
1100 \\
1200 \\
1300 \\
1400 \\
1500 \\
1100 \\
1100 \\
1100 \\
1100\end{array}$ & $\begin{array}{c}500 \\
1 \\
1 \\
300 \\
400 \\
600 \\
800\end{array}$ & $\begin{array}{l}1.99 \\
2.01 \\
2.00 \\
1\end{array}$ & $\begin{array}{r}0.909 \\
.911 \\
.902 \\
.908 \\
.912 \\
.912 \\
.912 \\
.912 \\
.913 \\
.918 \\
.916 \\
.906 \\
.897\end{array}$ \\
\hline $\mathrm{H} 3$ & $\begin{array}{l}87 \\
88 \\
\end{array}$ & $\begin{array}{l}1100 \\
1100\end{array}$ & $\begin{array}{l}500 \\
500\end{array}$ & $\begin{array}{l}1.01 \\
1.49\end{array}$ & $\begin{array}{r}0.903 \\
.902\end{array}$ \\
\hline$\overline{L 1}$ & $\begin{array}{l}115 \\
117 \\
118 \\
119 \\
121 \\
122 \\
123 \\
124 \\
125 \\
126 \\
127 \\
\end{array}$ & $\begin{array}{l}1100 \\
800 \\
950 \\
1100 \\
1300 \\
1100 \\
1100 \\
\end{array}$ & $\begin{array}{r}500 \\
300 \\
500 \\
800 \\
1100 \\
800 \\
650 \\
500 \\
300 \\
500 \\
500 \\
\end{array}$ & $\prod_{1.50}$ & $\begin{array}{r}0.915 \\
.921 \\
.915 \\
.907 \\
.901 \\
.901 \\
.909 \\
.916 \\
.924 \\
.917 \\
.914 \\
\end{array}$ \\
\hline$M 1$ & 114 & 1100 & 500 & 1.52 & 0.918 \\
\hline $\mathrm{M} 2$ & $\begin{array}{l}108 \\
109 \\
110 \\
111 \\
112 \\
113 \\
114\end{array}$ & $\begin{array}{l}1100 \\
1200 \\
1100 \\
1400 \\
1300 \\
1100 \\
1.100\end{array}$ & $\begin{array}{l}500 \\
700 \\
500 \\
700 \\
650 \\
500 \\
500\end{array}$ & $\begin{array}{l}1.00 \\
1.50 \\
1.50 \\
2.00 \\
2.00 \\
2.00 \\
1.52\end{array}$ & $\begin{array}{r}0.918 \\
.914 \\
.917 \\
.916 \\
.915 \\
.914 \\
.918\end{array}$ \\
\hline 01 & 90 & 500 & 420 & 1.00 & 0.937 \\
\hline 02 & $\begin{array}{l}91 \\
92 \\
\end{array}$ & $\begin{array}{l}1100 \\
1100\end{array}$ & $\begin{array}{l}500 \\
500 \\
\end{array}$ & $\begin{array}{l}1.00 \\
2.00 \\
\end{array}$ & $\begin{array}{r}0.937 \\
.940 \\
\end{array}$ \\
\hline$P 1$ & $\begin{array}{l}177 \\
178 \\
180 \\
182\end{array}$ & $\left.\right|_{1} ^{1100}$ & 1 & $\begin{array}{l}1.00 \\
1.50 \\
2.00 \\
2.00\end{array}$ & $\begin{array}{r}0.950 \\
.962 \\
.965 \\
.965\end{array}$ \\
\hline $\mathrm{P} 2$ & $\begin{array}{l}173 \\
174 \\
175 \\
176\end{array}$ & $\begin{array}{l}1100 \\
1100 \\
1100 \\
1300\end{array}$ & $\begin{array}{l}500 \\
500 \\
500 \\
600\end{array}$ & $\begin{array}{l}1.00 \\
1.50 \\
2.00 \\
2.00\end{array}$ & $\begin{array}{r}0.957 \\
.960 \\
.960 \\
.960 \\
\end{array}$ \\
\hline$\overline{\mathrm{p} 3}$ & $\begin{array}{l}168 \\
169 \\
170 \\
171 \\
172\end{array}$ & $\left.\right|_{1100} ^{1100}$ & $\begin{array}{c}500 \\
1 \\
600 \\
600\end{array}$ & $\begin{array}{l}1.00 \\
1.50 \\
1.51 \\
2.00 \\
2.00\end{array}$ & $\begin{array}{r}0.957 \\
.959 \\
.956 \\
.959 \\
.960\end{array}$ \\
\hline
\end{tabular}


Table II Concluded

\begin{tabular}{|c|c|c|c|c|c|}
\hline \multicolumn{3}{|c|}{ Probe Position 2} & \multirow[b]{2}{*}{$\begin{array}{l}\text { Accelerator Grid } \\
\text { Yoltage, volts }\end{array}$} & \multirow[b]{2}{*}{$\begin{array}{l}\text { Beam } \\
\text { Current, } \\
\text { amps }\end{array}$} & \multirow[b]{2}{*}{ Thrust Factor } \\
\hline Grid Set & Data Run Number & $\begin{array}{c}\text { Net Ion } \\
\text { Accelerating } \\
\text { Voltage, volts }\end{array}$ & & & \\
\hline D1 & $\begin{array}{l}219 \\
220 \\
221 \\
222 \\
223 \\
224 \\
225 \\
226 \\
227 \\
228 \\
229 \\
230 \\
233 \\
234 \\
235 \\
236 \\
237 \\
238 \\
239 \\
\end{array}$ & $\begin{array}{r}1250 \\
1100 \\
900 \\
700 \\
500 \\
1100 \\
1080 \\
800 \\
1000 \\
1250 \\
1000 \\
700 \\
400 \\
1250 \\
1100 \\
800 \\
400 \\
1100 \\
1100 \\
\end{array}$ & $\begin{array}{r}350 \\
500 \\
700 \\
900 \\
1100 \\
500 \\
520 \\
400 \\
500 \\
350 \\
600 \\
900 \\
1200 \\
350 \\
500 \\
800 \\
1200 \\
500 \\
500 \\
\end{array}$ & $\begin{array}{l}2.00 \\
1.50 \\
1.51 \\
1.50 \\
\cdot \mid \\
1 \\
1.00 \\
.50 \\
.50\end{array}$ & $\begin{array}{r}0.977 \\
.974 \\
.970 \\
.965 \\
.954 \\
.971 \\
.971 \\
.971 \\
.971 \\
.974 \\
.970 \\
.962 \\
.942 \\
.966 \\
.964 \\
.957 \\
.935 \\
.952 \\
.950\end{array}$ \\
\hline E1 & $\begin{array}{l}188 \\
189 \\
190 \\
191 \\
192 \\
193 \\
194 \\
195\end{array}$ & $\begin{array}{r}1100 \\
1100 \\
1100 \\
1250 \\
900 \\
600 \\
1100 \\
1100\end{array}$ & $\begin{array}{r}500 \\
500 \\
500 \\
350 \\
700 \\
1000 \\
350 \\
700\end{array}$ & $\begin{array}{c}1.00 \\
1.50 \\
2.01 \\
2.02 \\
2.00 \\
\square\end{array}$ & $\begin{array}{r}0.966 \\
.974 \\
.979 \\
.981 \\
.973 \\
.959 \\
.980 \\
.974\end{array}$ \\
\hline$\overline{F 2}$ & $\begin{array}{l}196 \\
199 \\
201\end{array}$ & $\begin{array}{l}1100 \\
1100 \\
1100\end{array}$ & $\begin{array}{l}500 \\
500 \\
500\end{array}$ & $\begin{array}{l}2.00 \\
1.81 \\
2.00\end{array}$ & $\begin{array}{r}0.924 \\
.925 \\
.922 \\
\end{array}$ \\
\hline$\overline{\mathrm{H} 2}$ & $\begin{array}{l}202 \\
214 \\
\end{array}$ & $\begin{array}{l}1100 \\
1075\end{array}$ & $\begin{array}{l}500 \\
500 \\
\end{array}$ & $\begin{array}{l}2.00 \\
1.92 \\
\end{array}$ & $\begin{array}{r}0.924 \\
.924 \\
\end{array}$ \\
\hline $\mathrm{J} 1$ & $\begin{array}{l}207 \\
208 \\
209 \\
210 \\
213\end{array}$ & $\begin{array}{l}1075 \\
1075 \\
1075 \\
1200 \\
1075\end{array}$ & $\begin{array}{l}500 \\
500 \\
500 \\
400 \\
500\end{array}$ & $\begin{array}{r}1.92 \\
1.91 \\
1.97 \\
1.32 \\
.97\end{array}$ & $\begin{array}{r}0.951 \\
.952 \\
.956 \\
.957 \\
.947\end{array}$ \\
\hline $\mathrm{K} 1$ & 217 & 1100 & 300 & 0.13 & 0.960 \\
\hline N1 & $\begin{array}{l}240 \\
241 \\
242 \\
243 \\
244\end{array}$ & $\begin{array}{l}1100 \\
1080 \\
1200 \\
1200 \\
1320\end{array}$ & $\begin{array}{l}500 \\
400 \\
400 \\
400 \\
360\end{array}$ & $\begin{array}{r}2.00 \\
1.93 \\
1.31 \\
1.34 \\
.81\end{array}$ & $\begin{array}{r}0.977 \\
.979 \\
.976 \\
.965 \\
.968\end{array}$ \\
\hline $\mathrm{P1}$ & $\begin{array}{l}183 \\
184 \\
185 \\
186 \\
187\end{array}$ & $\begin{array}{r}1100 \\
600 \\
1100 \\
1100 \\
1100\end{array}$ & $\begin{array}{l}500 \\
400 \\
500 \\
600 \\
500\end{array}$ & $\begin{array}{l}1.01 \\
1.00 \\
1.51 \\
2.01 \\
2.01\end{array}$ & $\begin{array}{r}0.963 \\
.963 \\
.967 \\
.967 \\
.969\end{array}$ \\
\hline
\end{tabular}


1. Bartz, D. R., and Horsewood, J. L., "CharacterIst1cs, Capabilities, and Costs of Solar Electric Spacecraft for Planetary Missions," Journal of Spacecraft and Rockets, Vol. 7, No. 12, Dec. 1970, Pp: 1379-1390.

2. Strack, W. C., and Hrach, F. J., "Early Application of Solar-Electric Propulsion of a 1Astronomical-Unit Out-of-the-Ecliptic Mission," TN D-5996, 1970, NASA, Cleveland, Ohto.

3. Rawlin, V. K., Banks, B. A., and Byers, D. C., "Design, Fabrication, and Operation of Dished Accelerator Grids on a 30-cm Ion Thruster," Paper 72-486, Apr. 1972, AIAA, New York, N.Y.

4. King, H. J., and Poeschel, R. L., "Low Voltage $30 \mathrm{~cm}$ Ion Thruster," NASA CR-120919, Feb. 1972, Hughes Research Labs., Malibu, Calif.

5. Rawlin, V. K., "Performance of 30-cm Ion Thrusters with Dished Accelerator Grids," to be published.
6. Finke, R. C., Holmes, A. D., and Keller, T. A., "Space Environment Facility for Electric Propulsion Systems Research," TN D-2774, 1965, NASA, Cleveland, Ohio.

7. Staff of Lewis Research Center, "Central Automatic Data Processing System," TN-4212, 1958, NACA, Cleveland, Ohio.

8. Ak1ma, H., "A New Method of Interpolation and Smooth Curve Fitting Based on Local Procedures," Journal of the Association for Computing Mach1nery, Vol. 17, No. 4, Oct. 1970, pp. 589-602.

9. Lathem, W. C., "Approximate Analysis of the Effects of Electrode Misalinements on Thrust Vector Control In Kaufman Thrusters," Paper 68-89, Jan. 1968, AIAA, New York, N.Y.

10. Lathem, W. C., and Adam, W. B., "Theoretical Analysis of a Grid-Translation Beam Deflection System for a 30-cm Diameter Kaufman Thruster," TM X-67911, 1971, NASA, Cleveland, Ohio. 


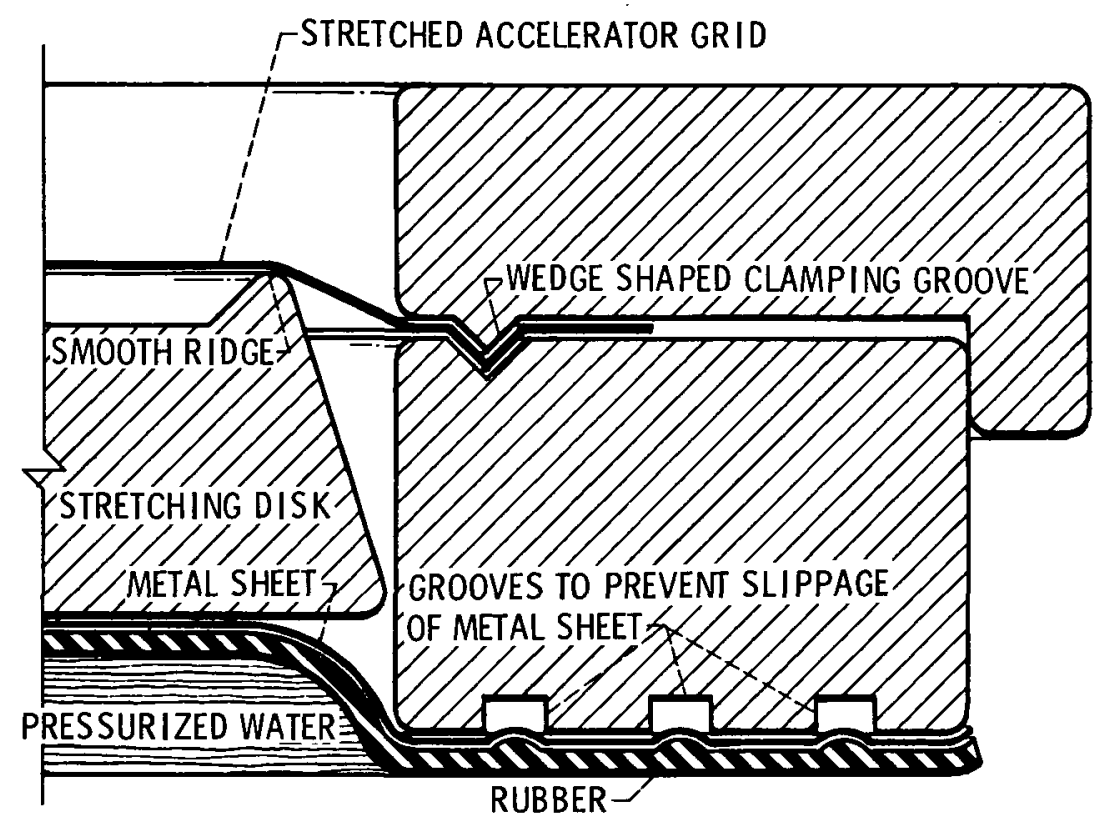

Figure 1. - Stretching system for accelerator grid.

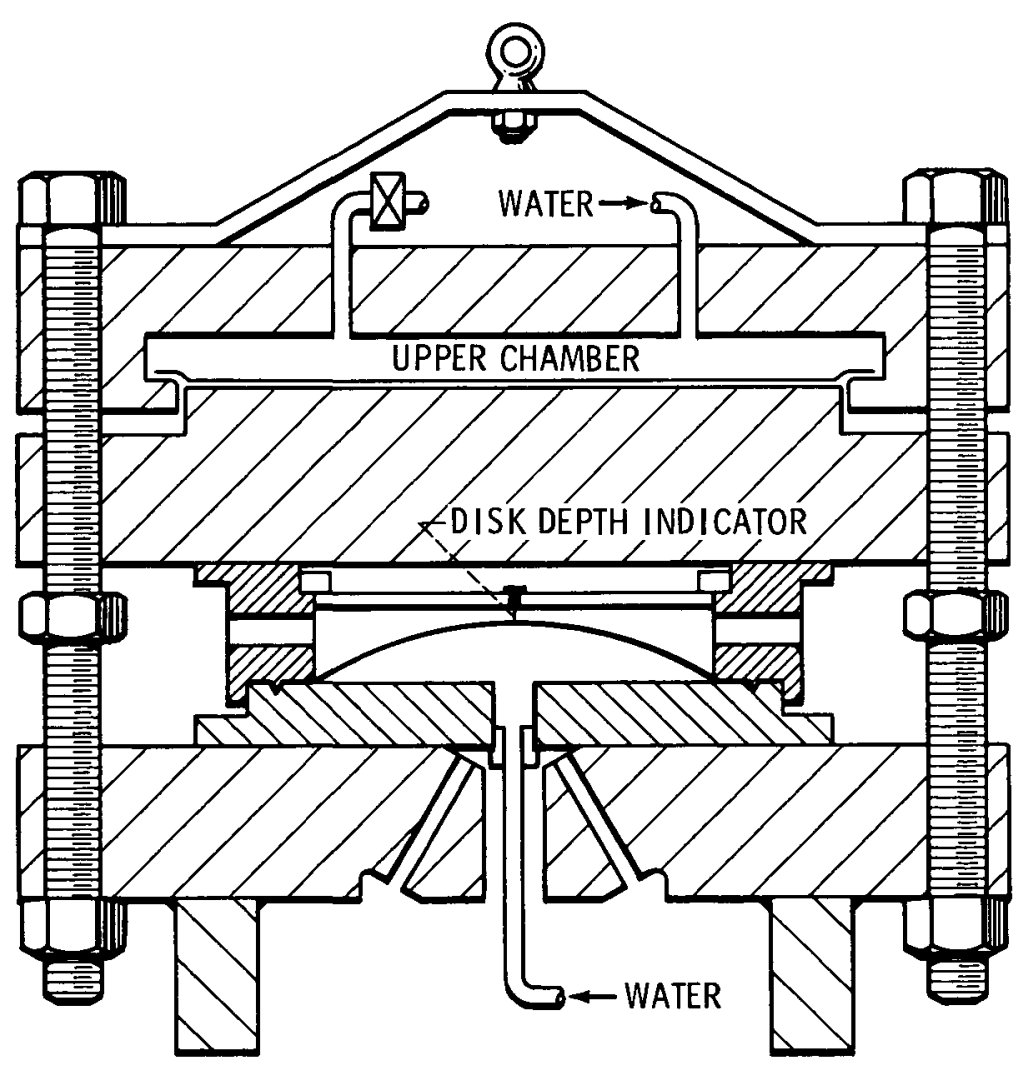

Figure 2. - Section view of hydroforming system. 


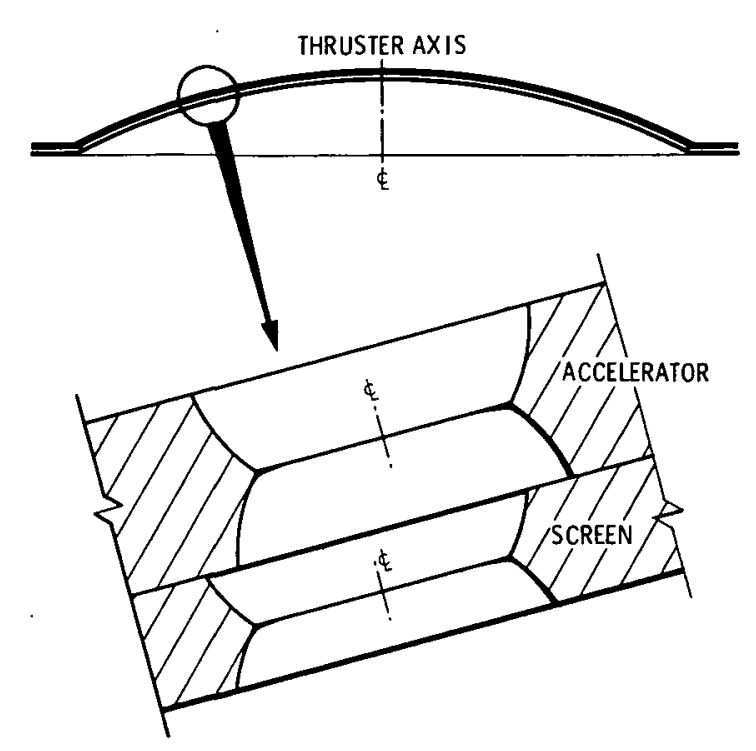

(a) AFTER SIMULTANEOUSLY HYDROFORMING THE CENTERS OF THE GRID HOLES ARE LOCATED APPROXIMATELY DOWNSTREAM OF EACH OTHER (NO COMPENSATION).

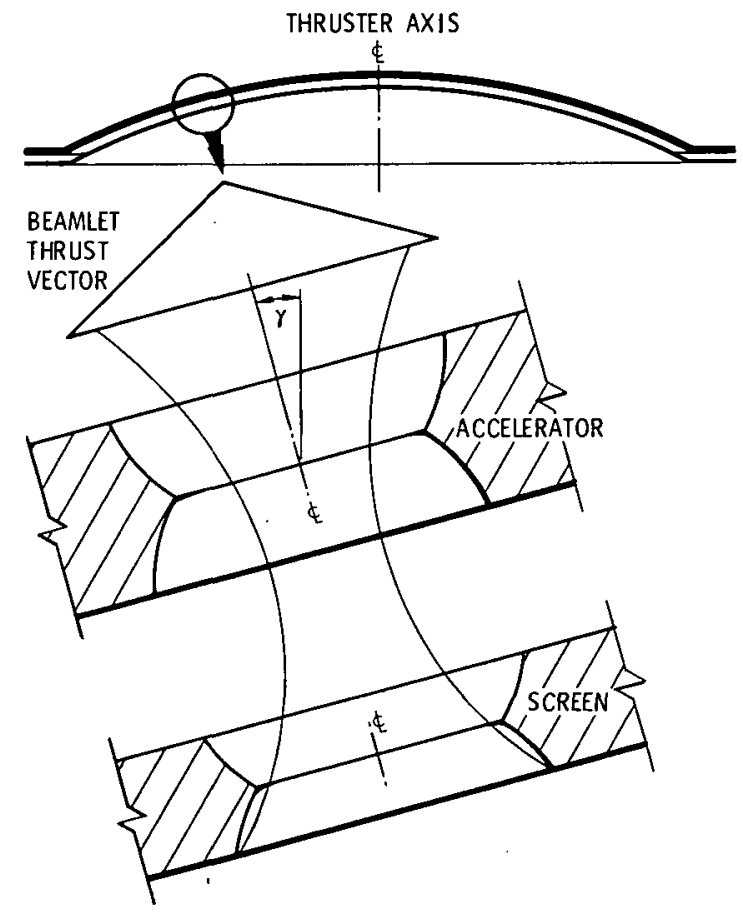

(c) DISHED GRIDS WITH COAXIAL APERATURES WHICHELIMINATE THE $\lambda$ THRUST LOSS.

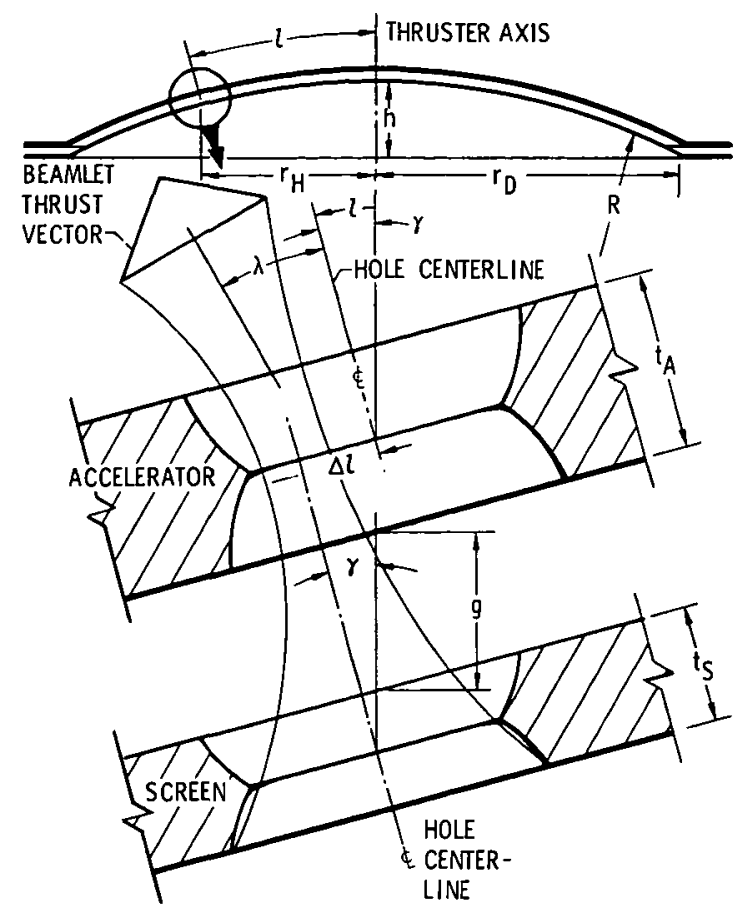

(b) AXIALLY DISPLACED DISHED GRIDS (NO COMPENSATION).

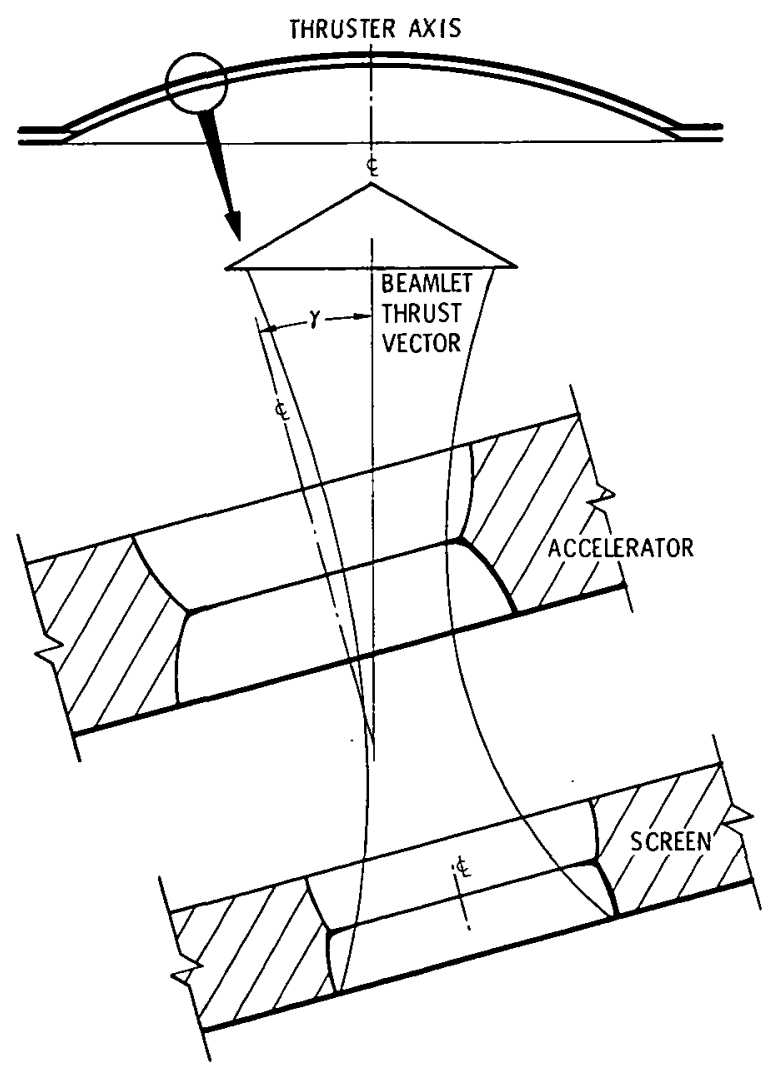

(d) DISHED GRID COMPENSATED FOR $\lambda$ AND $\gamma$ THRUST LOSSES.

Figure 3. - Section views of dished grid configurations. 


$$
1
$$



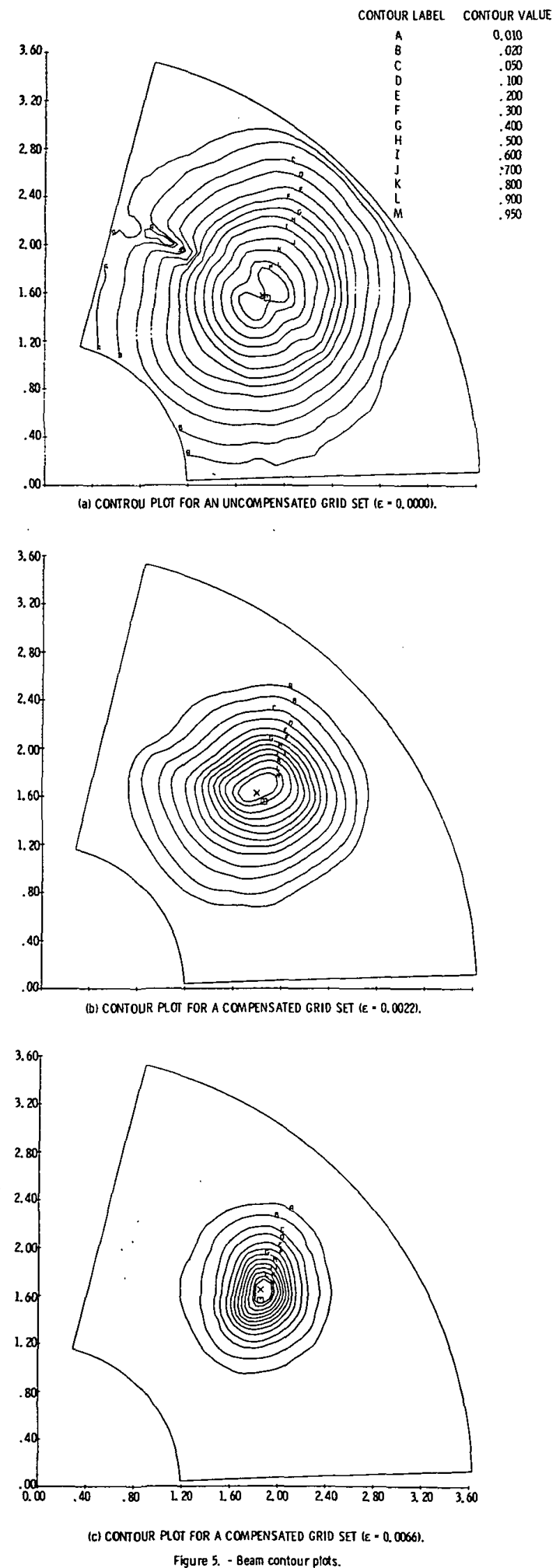


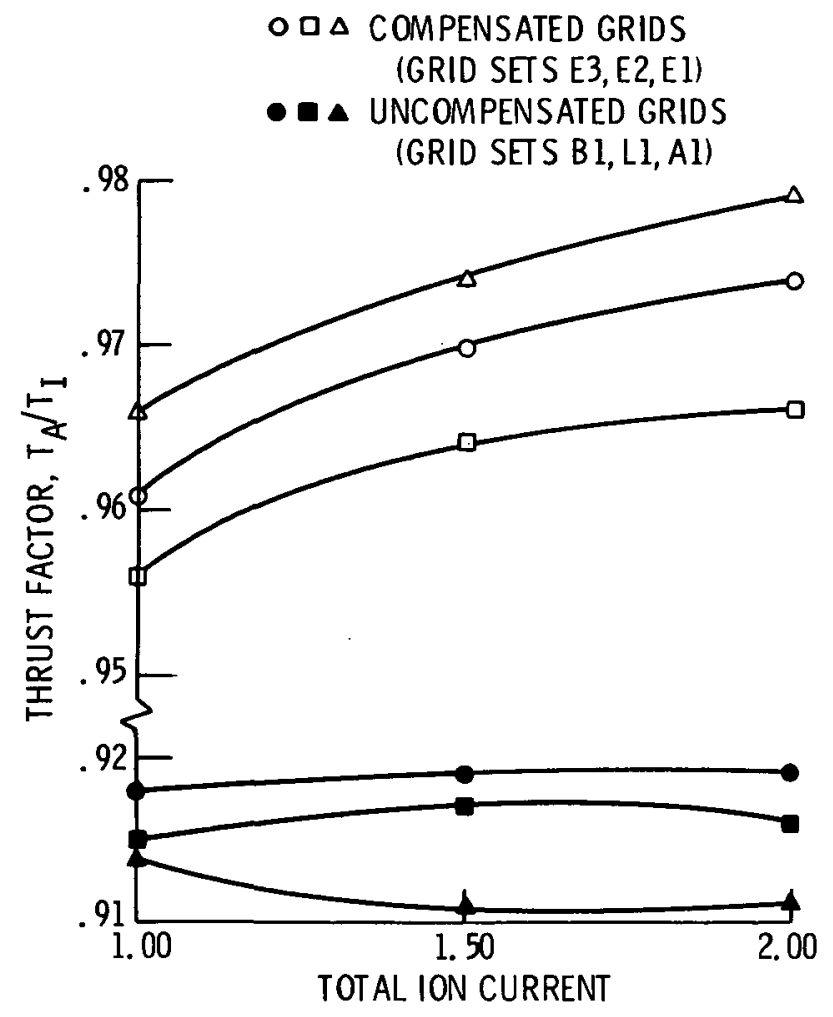

Figure 6. - Thrust factor versus total ion current.

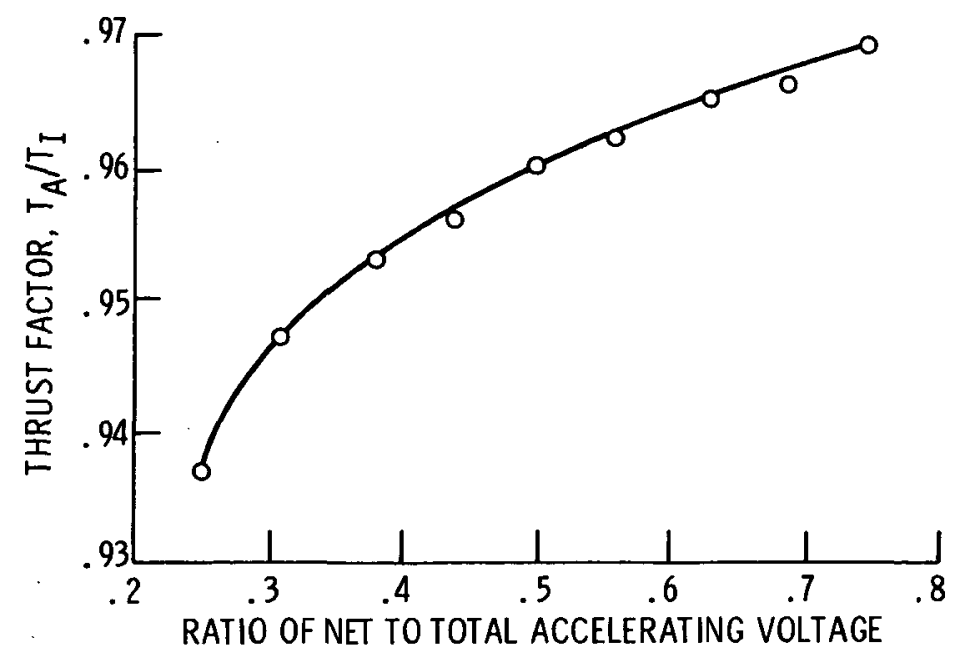

Figure 7. - Thrust factor versus ratio of net to total accelerating voltage for grid set E2. 